and recording apparatus was in an adjacent room. Response times were measured on two electronic timers accurate to $10^{-6} \mathrm{sec}$. Measurements were taken to the nearest millisecond.

\section{SUBJECTS}

The control groups of normal Ss were all male students aged 18-21 years. Ten were left-handed and 20 were right-handed. The two acallosal patients were selected from a group of 12 living in different parts of Australia and drawn to the author's attention by neurologist colleagues. The reasons for selecting these two for detailed study were (1) that they were able and willing to visit the laboratory for testing, and (2) because the neurologists' assessments made it highly probable that other cerebral abnormalities, other than the absence of the corpus callosum, were either totally or almost totally lacking. Detailed neurological reports of these patients, including pneumoencephalograms and ventriculograms, are given elsewhere (Jeeves, 1965), as also are details of basic psychometric testing. One was a boy of 14 years and the other a man of 46 years.

\section{RESULTS AND DISCUSSION}

Each $S$ made 300 responses with each hand under each of the two conditions of nasal and temporal retina stimulation. These responses were made to an equal number of stimuli presented in the right and left visual fields. Table 1 presents the mean response times for short-pathway and long-pathway responding for 30 normals and two acallosals. Ten of the normals were right-handed and responded with both hands, 10 were left-handed and responded with both hands, and a further 10 were right-handed and responded single-handedly. The acallosal boy came to the laboratory for testing for 5 days a week as did the normal Ss. The acallosal man lived 100 miles from the laboratory and was available for testing for one 3 -h period only, during a business visit to the city.

It is clear that all groups of normals gave shorter interhemispheric transmission times than the two acallosals. There were no differences between right- and left-handed Ss in ITTs. A comparison of the ITTs of the 20 normals and the two acallosals, under the nasal-stimulation/two-hands-responding condition, gave a Mann-Whitney $\mathrm{U}=0$, $\mathrm{p}<.01$ (one-tailed test). Referring to Table 1 , the results obtained when stimulating the nasal part of the retina show that the difference between short- and long-pathway responding for the three groups of normals, right-handed both hands responding, left-handed both hands responding, and right-handed single hand responding, were $1.80 \mathrm{msec}, 1.65 \mathrm{msec}$, and $2.56 \mathrm{msec}$, respectively. The comparable figures for the acallosal boy and the acallosal man were $19.5 \mathrm{msec}$ and $61.33 \mathrm{msec}$. When the temporal part of the retina was stimulated the figures for the same three groups of normals were $1.56 \mathrm{msec}$, $1.30 \mathrm{msec}$, and $3.09 \mathrm{msec}$, and for the acallosal boy, $14.5 \mathrm{msec}$. Again, comparing the 20 normal Ss on the two-handed condition with the acallosal boy, a Mann-Whitney $U=0, p=.05$ (one-tailed test) was obtained. No data under this condition were available for the acallosal man.

To test for the significance of the observed differences between short- and long-path way responding in the normals, the data for all groups were combined, making a total of $30 \mathrm{Ss}$. The difference scores between long and short pathway for nasal and temporal stimulation were then analyzed separately using a Wilcoxon matched-pairs signed rank test. This gave $\mathrm{z}$ (nasal) $=3.1$ $(\mathrm{p}<.001)$ and $\mathrm{z}$ (temporal $)=4.0(\mathrm{p}<.005)$. The interhemispheric transmission time for the acallosal man was unexpectedly long and one wonders whether the fact that he was the only $S$ who completed all his responding on one day had anything to do with this. Against this explanation is the fact that the greatly lengthened interhemispheric transmission time did not develop towards the end of the testing period, but was evident throughout. Moreover, his mean response time for short-pathway responding was within the range of performance of normal Ss. As regards the boy's lengthened interhemispheric transmission time, any attempt to explain this as being due solely to his being younger than the normal adult controls is ruled out by the finding that normal 10-year-old children show interhemispheric transmission times within the same range as the normal adults in this experiment.

The interhemispheric transmission time for the normals is within the range reported by earlier workers for the visual modality (Poffenberger, 1912), and for other modalities such as touch (Efron, 1963;
Moskatova, 1966). The interhemispheric transmission times for acallosals is so much greater than for the normals that one is left speculating as to what possible hemispheric pathway could take so long. If the alternate pathway is subcortical, it may, in addition to being longer than a transcallosal pathway, also be more diffuse and involve several additional synaptic junctions. Whatever specific speculations may be entertained concerning alternate interhemispheric pathways utilized by acallosal patients, the results reported above strengthen the earlier suggestion (Jeeves, 1965) that the reduced efficiency of acallosals on tasks involving bimanual perceptuomotor coordination under speed stress may be attributed partly to lengthened interhemispheric transmission times.

\section{REFERENCES}

EFRON, R. The effect of handedness on the perception of simultaneity and temporal order. Brain, 1963, 86, 261-284.

GAZZANIGA, M. S., BOGEN, J. E., \& SPERRY, R. W. Observations on visual perception after disconnexion of the cerebral hemispheres in man. Brain, 1965, 88, 221-236.

JEEVES, M. A. Psychological studies of three cases of congenital agenesis of the corpus callosum in man. In CIBA Foundation Study Group No. 20 (Eds.), Functions of the corpus collosum. London: Churchill, 1965. Pp. 73-94.

MOSKATOVA, A. K. Simple motor reaction time to tactile stimulation. Voprosy Psikhologii, $1966,2,68-74$

POFFENBERGER, A. T. Reaction time to retinal stimulation with special reference through nerve centres. Archives of Psychology, 1912, 23, 1 .

SPERRY, R. W. Brain bisection and mechanisms of consciousness. In J.C. Eccles (Ed.), Brain and conscious experience. New York: Springer-Veriag, 1966.

SPERRY, R. W., \& GAZZANIGA, M.S. Language following surgical disconnection of the hemispheres. In C. H. Millikan (Ed.), Brain mechanisms underlying speech and language. New York: Grune \& Stratton, 1967. Pp. 108-121.

SPERRY, R. W. Hemisphere deconnection and unity in conscious awareness. American Psychologist, 1968, 23, 723-733.

\title{
The role of discontinuous US in discriminated avoidance learning '
}

\section{G. B. BIEDERMAN, University of Toronto, Toronto, Ontario, Canada.}

A test of the hypothesis that responses in the off-cycle of discontinuous shock facilitates avoidance responding by generalization to the CS-US interval was performed by causing the stimulus conditions during the off-cycle to be dissimilar to the conditions in the CS-US interval. Avoidance performance was enhanced despite the stimulus differences, suggesting that the generalization hypothesis is incorrect. 
Hess \& Shafer (1968) report an attempt to test the hypothesis that discontinuous shock facilitates discliminated avoidance conditioning by the generalization of the escape response, in an off-shock period, to the CS-US interval. The hypothesis had been suggested by D'Amato, Keller, \& DiCara (1964), and Biederman, D'Amato, \& Keller (1964). In their experiment, Hess \& Shafer (1968) provide a shock contingent upon each escape response in the off-shock phase; it was expected that avoidance performance would be retarded as a result of the decrease in the similarity of the off-shock period to the CS-US interval. No decrement was obtained, however, when experimental groups were compared with control groups receiving usual discontinuous shock.

D'Amato, Etkin, \& Fazzaro (1968) report further evidence (of an indirect nature) that the generalization hypothesis may be incorrect; discontinuous US failed to promote anticipatory responding when the avoidance contingency was removed with escape still possible. Presumably anticipatory responding is a necessary stage in the eventual acquisition of the avoidance contingency.

The present experiment evaluates the generalization hypothesis by the manipulation of the CS present in the off-shock period, following a failure to avoid. The CS was either terminated at the conclusion of the avoidance period or was permitted to remain in effect until terminated by an escape response. Experimental groups were thus presented with an off-shock stimulus situation which

Table 1

Mean Per Cent CRs with Avoidance Contingency in Force

\begin{tabular}{lrrr}
\multicolumn{4}{c}{ Contingency in Force } \\
\hline & $\begin{array}{c}\text { CS } \\
\text { Present } \\
\text { During } \\
\text { Escape }\end{array}$ & $\begin{array}{c}\text { CS } \\
\text { Absent } \\
\text { During } \\
\text { Escape }\end{array}$ & Total \\
\hline $\begin{array}{l}\text { Continuous } \\
\text { Shock }\end{array}$ & 13.37 & 4.04 & 17.41 \\
$\begin{array}{l}\text { Discontinuous } \\
\text { Shock }\end{array}$ & 30.37 & 8.00 & 38.37 \\
Total & 43.74 & 12.04 & \\
\hline
\end{tabular}

Table 2

Mean Per Cent CRs with Avoidance Contingency Removed

\begin{tabular}{lccc}
\hline & $\begin{array}{c}\text { CS } \\
\text { Present } \\
\text { During } \\
\text { Escape }\end{array}$ & $\begin{array}{c}\text { CS } \\
\text { Absent } \\
\text { During } \\
\text { Escape }\end{array}$ & Total \\
\hline $\begin{array}{l}\text { Continuous } \\
\text { Shock }\end{array}$ & 3.08 & 1.54 & 4.62 \\
$\begin{array}{l}\text { Discontinuous } \\
\text { Shock }\end{array}$ & 5.75 & 6.62 & 12.37 \\
Total & 8.83 & 8.16 & \\
\hline
\end{tabular}

differed from the CS-US interval stimulus condition. If the generalization hy pothesis is correct, avoidance should not benefit from discontinuous shock for groups without CS during escape.

D’Amato, Etkin, \& Fazzaro (1968) have suggested that anticipatory responding be evaluated by appropriate control groups; in the present experiment, the main variables were investigated by removing the avoidance contingency for certain groups, while recording CRs (responses in the preshock period).

\section{SUBJECTS}

Subjects were 48 male Wistar rats, approximately 90 days of age, obtained from Canadian Research Animal Farms, Bradford, Ontario.

\section{APPARATUS AND PROCEDURE}

The apparatus was of the type described previously (Biederman, 1968), consisting of four single-bar Skinner boxes with independent automatic programming instrumentation. Shock was continuous or discontinuous (.2 sec on, $2 \mathrm{sec}$ off); CS, which consisted of white noise (which brought the noise level to $80 \mathrm{~dB}$ ) was terminated at the conclusion of the CS-US interval, or was continued until escape occurred. The avoidance contingency was in force or was eliminated. These variables contributed to a 2 by 2 by 2 factorial design, with $N=6$ in each condition, randomly assigned. A VI $45-\mathrm{sec}$ intertrial interval was used. The initial response in the CS-US interval was considered the CR when the avoidance contingency was removed, and a second response was required to escape shock. The onset of shock was programmed so that a minimum of $1 \mathrm{sec}$ separated a nonavoidance $C R$ and US (D'Amato et al, 1968).

On Day 1, Ss received 40 shaping trials under continuous shock, or 20 continuous shock trials followed by 20 discontinuous trials for discontinuous shock groups. On Day 2, 500 trials were presented with the experimental conditions in force. A $1.0-\mathrm{mA}$ shock was used throughout the experiment.

\section{RESULTS AND DISCUSSION}

The dependent measure used throughout the following analysis is mean per cent CRs for the last 400 trials of Day 2. The continuous vs discontinuous shock main effect was significant $(F=4.45, \mathrm{df}=1 / 40$, $\mathrm{p}<.05)$, as were the main effects of $\mathrm{CS}$ termination condition $(F=5.66, \mathrm{df}=1 / 40$, $\mathrm{p}<.025)$, and avoidance vs nonavoidance condition $(\mathrm{F}=8.12, \mathrm{df}=1 / 40, \mathrm{p}<.01)$.

There was no interaction between type of shock and CS termination conditions $(\mathrm{F}<1)$. Inspection of Table 1, which presents summary data for groups having the possibility of avoidance, and Table 2 , which summarizes data for $S s$ without the avoidance contingency, reveals that discontinuous shock facilitates the production of CRs regardless of the CS condition during escape. This is consistent with the findings of Hess \& Shafer (1968), and confirms their conclusion that the generalization hypothesis does not account for the facilitating effect of discontinuous shock in avoidance learning.

The complexity of stimulus control in discriminated avoidance conditioning is illustrated by the significant interaction between $\mathrm{CS}$ termination condition and avoidance-nonavoidance contingency conditions (which was the only significant interaction; $\mathrm{F}=5.20$, $\mathrm{df}=1 / 40, \mathrm{p}<.05$ ). Table 2 shows that the presence or absence of CS in escape has no significant effect on anticipatory responding; when the avoidance contingency is in force, there is a marked increase in CRs produced when CS is present in escape (Table 1).

The low level of mean per cent CRs produced by $S s$ in this experiment is consistent with the results of Hess \& Shafer (1968). The level of anticipatory responding is generally consistent with that of D'Amato et al (1968) for high-shock groups.

In summary, the cause of the facilitory effect of discontinuous shock remains undemonstrated. It seems quite likely that discontinuous shock exerts its effects, not by its enhancement of the learning of the avoidance contingency, but rather by the accidental elimination of incompatible responses such as bar-holding and freezing, which present a great obstacle in avoidance performance. Observation of escape performance reveals that rats undergoing discontinuous shock are far more likely to vary their position in shock-off periods.

\section{REFERENCES}

BIEDERMAN, G. B. Discriminated avoidance conditioning: CS function during avoidance acquisition and maintenance. Psychonomic Science, 1968, 10, 23-24.

BIEDERMAN, G. B., D'AMATO, M. R., \& KELLER, D. M. Facilitation of discriminated avoidance learning by dissociation of CS and manipulandum. Psychonomic Science, 1964, 1, 229-230.

D'AMATO, M. R., ETKIN, M., \& FAZZARO, J. Effects of shock type and intensity on anticipatory responses. Journal of Comparative \& Physiological Psychology, 1968, 66, 527-529.

D'AMATO, M. R., KELLER, D. M., \& DiCARA, L. Facilitation of discriminated avoidance learning by discontinuous shock. Journal of Comparative \& Physiological Psychology, 1964, $58,344-349$.

HESS, J. H., \& SHAFER, J. N. Discontinuous shock and generalization to the preshock period in discriminated avoidance learning. Psychonomic Science, 1968, 10, 175-176. NOTE

1. Supported by Grant 106 from the Canadian National Research Council and Grant 185 from the Ontario Mental Health Foundation. The assistance of $\mathrm{G}$. Heighington and $\mathrm{B}$. Heighington is gratefully acknowledged. 